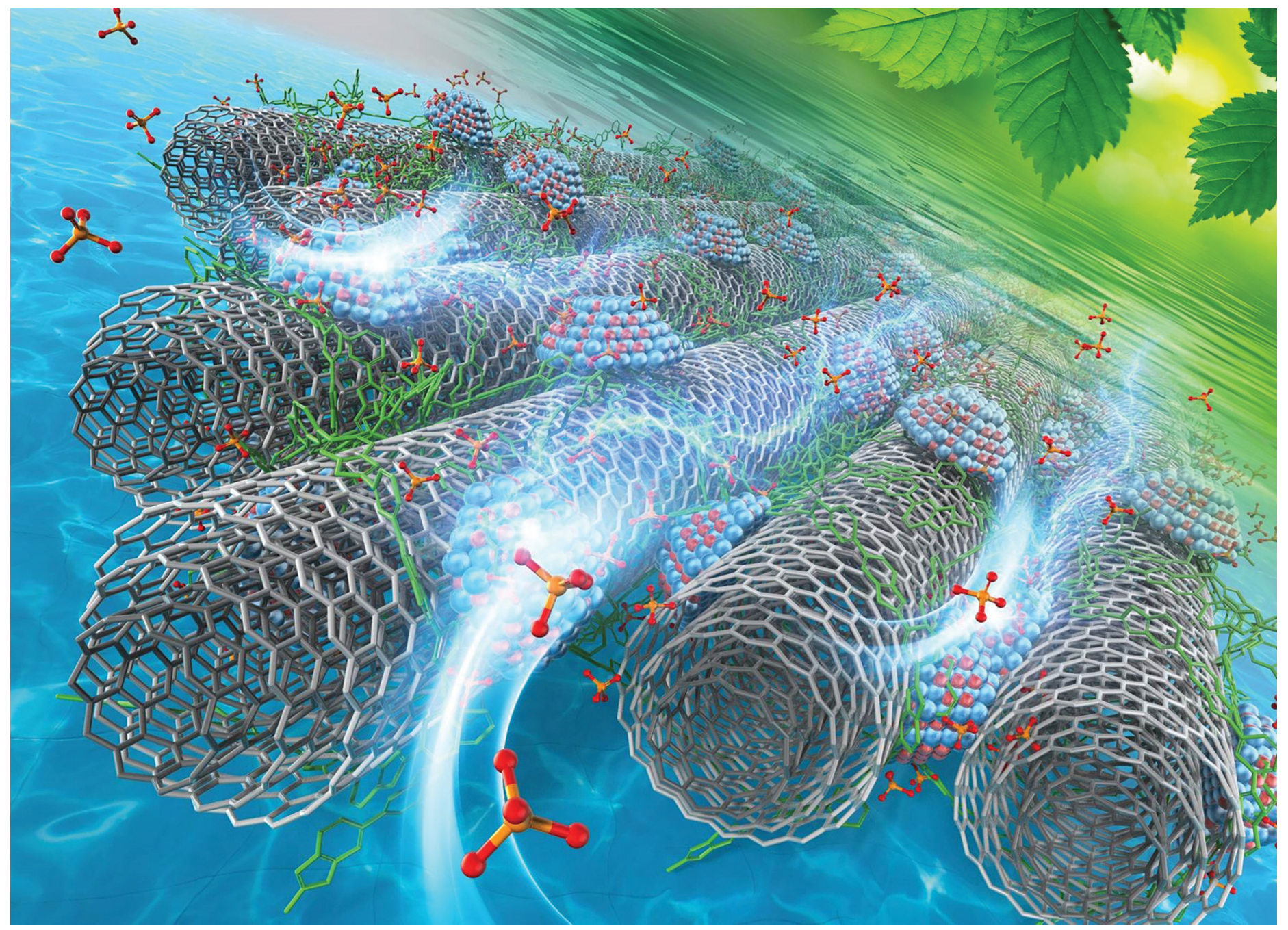

Showcasing research from electrochemistry laboratory of Professor Masato Tominaga, Graduate School of Science and Engineering, Saga University, Japan.

Highly sensitive detection of phosphate using well-ordered crystalline cobalt oxide nanoparticles supported by multi-walled carbon nanotubes

Electrochemical sensor for the detection of phosphate with great sensing properties has successfully developed based on CoONPs hybridized with PBI and MWCNTs. This work shows the CoONPs/PBI/MWCNT-modified glassy carbon electrode exhibited high sensitivity similar to the fluorescence and spectrophotometric methods due to the effects of morphology and microstructure resulting on better electrochemical performance. The modified electrode was able to detect low concentration of phosphate even below the eutrophication threshold making the electrode suitable for phosphate monitoring in environmental samples.

\section{As featured in:}

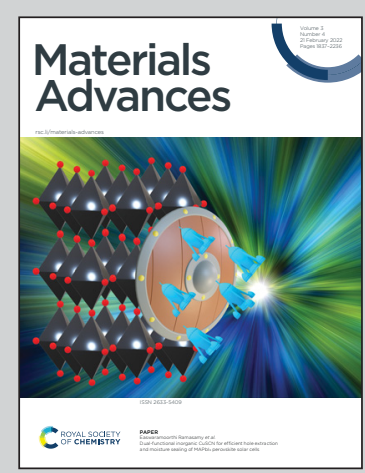

See Masato Tominaga et al., Mater. Adv., 2022, 3, 2018. 
Check for updates

Cite this: Mater. Adv., 2022, 3, 2018

Received 20th November 2021 Accepted 24th December 2021

DOI: 10.1039/d1ma01097b

rsc.li/materials-advances

\title{
Highly sensitive detection of phosphate using well-ordered crystalline cobalt oxide nanoparticles supported by multi-walled carbon nanotubes $\dagger$
}

\author{
Shaimah Rinda Sari, (iD a Masayuki Tsushida, ${ }^{\mathrm{b}}$ Tetsuya Sato ${ }^{\mathrm{b}}$ and \\ Masato Tominaga (D)*a
}

\begin{abstract}
Phosphates are well-known groundwater and surface water contaminants, with even modest increases
in their concentration contributing to the eutrophication of lakes and coastal waterways and thus
potentially harming the environment. Consequently, sensors capable of detecting phosphate ions at
concentrations below the eutrophication threshold $(0.1 \mu \mathrm{M})$ are highly sought after. Herein, cobalt oxide
nanoparticles (CoONPs) supported by polybenzimidazole (PBI)-modified multi-walled carbon nanotubes
(MWCNTs) were prepared and shown to feature uniform size (3.5-5.5 nm) and limited Co phase mainly
containing hexagonal $\mathrm{CO}_{3} \mathrm{O}_{4}$ and a minor amount of $\mathrm{CoO}$. The synthesized NPs exhibited better phos-
phate sensing performance than previously reported polycrystalline $\mathrm{Co}$ wires, i.e., the CoONPs/PBI/
MWCNT-modified glassy carbon electrode could detect phosphate at pH 4 and 7 at levels of 0.1 to
Phosphates are well-known groundwater and surface water contaminants, with even modest increases
in their concentration contributing to the eutrophication of lakes and coastal waterways and thus
potentially harming the environment. Consequently, sensors capable of detecting phosphate ions at
concentrations below the eutrophication threshold $(0.1 \mu \mathrm{M})$ are highly sought after. Herein, cobalt oxide
nanoparticles (CoONPs) supported by polybenzimidazole (PBI)-modified multi-walled carbon nanotubes
(MWCNTs) were prepared and shown to feature uniform size ( $3.5-5.5 \mathrm{~nm}$ ) and limited Co phase mainly
containing hexagonal $\mathrm{CO}_{3} \mathrm{O}_{4}$ and a minor amount of $\mathrm{CoO}$. The synthesized NPs exhibited better phos-
phate sensing performance than previously reported polycrystalline Co wires, i.e., the CoONPs/PBI/
MWCNT-modified glassy carbon electrode could detect phosphate at pH 4 and 7 at levels of 0.1 to

Phosphates are well-known groundwater and surface water contaminants, with even modest increases
in their concentration contributing to the eutrophication of lakes and coastal waterways and thus
potentially harming the environment. Consequently, sensors capable of detecting phosphate ions at
concentrations below the eutrophication threshold $(0.1 \mu \mathrm{M})$ are highly sought after. Herein, cobalt oxide
nanoparticles (CoONPs) supported by polybenzimidazole (PBI)-modified multi-walled carbon nanotubes
(MWCNTs) were prepared and shown to feature uniform size (3.5-5.5 nm) and limited Co phase mainly
containing hexagonal $\mathrm{CO}_{3} \mathrm{O}_{4}$ and a minor amount of $\mathrm{CoO}$. The synthesized NPs exhibited better phos-
phate sensing performance than previously reported polycrystalline $\mathrm{Co}$ wires, i.e., the CoONPs/PBI/
MWCNT-modified glassy carbon electrode could detect phosphate at pH 4 and 7 at levels of 0.1 to

Phosphates are well-known groundwater and surface water contaminants, with even modest increases
in their concentration contributing to the eutrophication of lakes and coastal waterways and thus
potentially harming the environment. Consequently, sensors capable of detecting phosphate ions at
concentrations below the eutrophication threshold $(0.1 \mu \mathrm{M})$ are highly sought after. Herein, cobalt oxide
nanoparticles (CoONPs) supported by polybenzimidazole (PBI)-modified multi-walled carbon nanotubes
(MWCNTs) were prepared and shown to feature uniform size ( $3.5-5.5 \mathrm{~nm}$ ) and limited Co phase mainly
containing hexagonal $\mathrm{CO}_{3} \mathrm{O}_{4}$ and a minor amount of $\mathrm{CoO}$. The synthesized NPs exhibited better phos-
phate sensing performance than previously reported polycrystalline Co wires, i.e., the CoONPs/PBI/
MWCNT-modified glassy carbon electrode could detect phosphate at pH 4 and 7 at levels of 0.1 to

Phosphates are well-known groundwater and surface water contaminants, with even modest increases
in their concentration contributing to the eutrophication of lakes and coastal waterways and thus
potentially harming the environment. Consequently, sensors capable of detecting phosphate ions at
concentrations below the eutrophication threshold $(0.1 \mu \mathrm{M})$ are highly sought after. Herein, cobalt oxide
nanoparticles (CoONPs) supported by polybenzimidazole (PBI)-modified multi-walled carbon nanotubes
(MWCNTs) were prepared and shown to feature uniform size (3.5-5.5 nm) and limited Co phase mainly
containing hexagonal $\mathrm{CO}_{3} \mathrm{O}_{4}$ and a minor amount of $\mathrm{CoO}$. The synthesized NPs exhibited better phos-
phate sensing performance than previously reported polycrystalline $\mathrm{Co}$ wires, i.e., the CoONPs/PBI/
MWCNT-modified glassy carbon electrode could detect phosphate at pH 4 and 7 at levels of 0.1 to

Phosphates are well-known groundwater and surface water contaminants, with even modest increases
in their concentration contributing to the eutrophication of lakes and coastal waterways and thus
potentially harming the environment. Consequently, sensors capable of detecting phosphate ions at
concentrations below the eutrophication threshold $(0.1 \mu \mathrm{M})$ are highly sought after. Herein, cobalt oxide
nanoparticles (CoONPs) supported by polybenzimidazole (PBI)-modified multi-walled carbon nanotubes
(MWCNTs) were prepared and shown to feature uniform size (3.5-5.5 nm) and limited Co phase mainly
containing hexagonal $\mathrm{CO}_{3} \mathrm{O}_{4}$ and a minor amount of $\mathrm{CoO}$. The synthesized NPs exhibited better phos-
phate sensing performance than previously reported polycrystalline $\mathrm{Co}$ wires, i.e., the CoONPs/PBI/
MWCNT-modified glassy carbon electrode could detect phosphate at pH 4 and 7 at levels of 0.1 to

Phosphates are well-known groundwater and surface water contaminants, with even modest increases
in their concentration contributing to the eutrophication of lakes and coastal waterways and thus
potentially harming the environment. Consequently, sensors capable of detecting phosphate ions at
concentrations below the eutrophication threshold $(0.1 \mu \mathrm{M})$ are highly sought after. Herein, cobalt oxide
nanoparticles (CoONPs) supported by polybenzimidazole (PBI)-modified multi-walled carbon nanotubes
(MWCNTs) were prepared and shown to feature uniform size (3.5-5.5 nm) and limited Co phase mainly
containing hexagonal $\mathrm{CO}_{3} \mathrm{O}_{4}$ and a minor amount of $\mathrm{CoO}$. The synthesized NPs exhibited better phos-
phate sensing performance than previously reported polycrystalline $\mathrm{Co}$ wires, i.e., the CoONPs/PBI/
MWCNT-modified glassy carbon electrode could detect phosphate at pH 4 and 7 at levels of 0.1 to

Phosphates are well-known groundwater and surface water contaminants, with even modest increases
in their concentration contributing to the eutrophication of lakes and coastal waterways and thus
potentially harming the environment. Consequently, sensors capable of detecting phosphate ions at
concentrations below the eutrophication threshold $(0.1 \mu \mathrm{M})$ are highly sought after. Herein, cobalt oxide
nanoparticles (CoONPs) supported by polybenzimidazole (PBI)-modified multi-walled carbon nanotubes
(MWCNTs) were prepared and shown to feature uniform size (3.5-5.5 nm) and limited Co phase mainly
containing hexagonal $\mathrm{CO}_{3} \mathrm{O}_{4}$ and a minor amount of $\mathrm{CoO}$. The synthesized NPs exhibited better phos-
phate sensing performance than previously reported polycrystalline $\mathrm{Co}$ wires, i.e., the CoONPs/PBI/
MWCNT-modified glassy carbon electrode could detect phosphate at pH 4 and 7 at levels of 0.1 to

Phosphates are well-known groundwater and surface water contaminants, with even modest increases
in their concentration contributing to the eutrophication of lakes and coastal waterways and thus
potentially harming the environment. Consequently, sensors capable of detecting phosphate ions at
concentrations below the eutrophication threshold $(0.1 \mu \mathrm{M})$ are highly sought after. Herein, cobalt oxide
nanoparticles (CoONPs) supported by polybenzimidazole (PBI)-modified multi-walled carbon nanotubes
(MWCNTs) were prepared and shown to feature uniform size ( $3.5-5.5 \mathrm{~nm}$ ) and limited Co phase mainly
containing hexagonal $\mathrm{CO}_{3} \mathrm{O}_{4}$ and a minor amount of $\mathrm{CoO}$. The synthesized NPs exhibited better phos-
phate sensing performance than previously reported polycrystalline $\mathrm{Co}$ wires, i.e., the CoONPs/PBI/
MWCNT-modified glassy carbon electrode could detect phosphate at pH 4 and 7 at levels of 0.1 to $100 \mathrm{nM}$, that is, below the eutrophication threshold of $0.1 \mu \mathrm{M}$.
\end{abstract}

\section{Introduction}

Phosphorus is involved in important physiological processes and is therefore an essential nutrient. In natural waters, phosphorus is typically present as phosphates, among which the inorganic orthophosphate form is more thermodynamically stable than other forms. ${ }^{1}$ However, phosphates are also wellknown contaminants of groundwater and surface water ${ }^{2}$ and are mainly transported from terrestrial ecosystems to aquatic ones via wind erosion, surface runoff, and leaching. The eutrophication caused by this transport may be further accelerated by agricultural activities (supply of phosphorus to crops as a fertilizer), animal husbandry, and other human activities. ${ }^{3}$ Under the right conditions, even a modest increase in phosphate concentration due to influx from agricultural land or other sources can contribute to the eutrophication of lakes and coastal waterways. Eutrophication refers to the overenrichment of natural waters in nutrients, such as phosphates, which leads to the excessive growth of algae and other aquatic plants and may cause the death of aquatic fauna due to the lack

\footnotetext{
${ }^{a}$ Graduate School of Science and Engineering, Saga University, 1 Honjomachi, Saga 840-8502, Japan. E-mail: masato@cc.saga-u.ac.jp

${ }^{b}$ Faculty of Engineering, Kumamoto University, 2-39-1 Kurokami,

Kumamoto 860-8555, Japan

$\dagger$ Electronic supplementary information (ESI) available: Additional CoONP characterization data. See DOI: 10.1039/d1ma01097b
}

of oxygen. ${ }^{3,4}$ The eutrophication threshold concentrations of phosphates have been estimated to be $0.1-0.32 \mu \mathrm{M} .{ }^{5}$ Given that the increase in the phosphate levels in rivers over the past 50 years ${ }^{6}$ has negatively affected aquatic ecology and water quality, phosphate ion monitoring is crucial for ensuring environmental safety.

Phosphate is typically quantified using (i) high-performance liquid chromatography, ${ }^{7}$ (ii) the colorimetric method of Murphy and Riley, ${ }^{8-10}$ and (iii) spectroscopic methods relying on the molybdenum blue reaction or a series of complicated sample pretreatments. ${ }^{11,12}$ All the above-mentioned methods require complex processes and are therefore poorly suited for phosphate monitoring. Other classical techniques such as gravimetric methods,${ }^{13}$ volumetric methods,${ }^{14}$ and instrumental methods based on chromatographic measurements ${ }^{15,16}$ also require sample pre-treatment and can therefore be timeconsuming, expensive, and/or produce toxic wastes. Such methods also had detection ranges higher than the eutrophication threshold of $0.1 \mu \mathrm{M}$.

Recent studies using colorimetric and ECL ${ }^{17}$ and fluorescence methods ${ }^{18}$ satisfy the requirement of lower detection range than the eutrophication threshold, however they are difficult to operate for on-site measurement of phosphate concentration. Hence, the development of inexpensive, easy to manufacture, and reliable sensors for monitoring phosphate concentration in agricultural wastewater and other aqueous systems is expected to benefit the mass production of food and 
agricultural products as well as help solve certain environmental problems.

In recent decades, considerable attention has been directed toward the development of electrochemical phosphate sensors in view of their simple operation, fast response, and high sensitivity. ${ }^{19}$ For example, a Co electrode has been successfully used as a base material for phosphate sensing, ${ }^{20}$ while the first Co-based phosphate sensor was reported in 1995 by Xiao et al. ${ }^{21}$ Co-based nanomaterials have attracted significant attention owing to their large specific surface area, which is reported to be $>10 \mathrm{~m}^{2} \mathrm{~g}^{-1}$ (beneficial for increasing the number of active sites), ${ }^{22}$ excellent conductivity, catalytic activity, and ability to sense phosphate. A phosphate sensor fabricated by coating a glassy carbon electrode (GCE) with Co oxide nanoparticles (NPs) and reduced graphene oxide exhibited a good linear potentiometric response. ${ }^{23}$ However, its lowest detection limit was $1 \mu \mathrm{M}$, which is higher than the eutrophication threshold. Herein, we synthesized CoONPs supported by polybenzimidazole (PBI)-modified multi-walled carbon nanotubes (MWCNTs) to detect phosphate ions with high sensitivity. MWCNTs were selected owing to their large surface-to-volume ratio, ${ }^{24}$ good conductivity, which makes them suitable for catalytic and sensor applications, ${ }^{25-29}$ and relatively low cost. ${ }^{30}$ The CoONPs featured a narrow size, well-distribution and well-defined limited crystal planes that provided sites specifically interacting with phosphate ions and enabled their sensitive detection.

\section{Experimental}

\section{Materials}

$\mathrm{N}, \mathrm{N}$-Dimethylacetamide (DMAc), polyethylene glycol 400 (PEG400), $\mathrm{Co}\left(\mathrm{CH}_{3} \mathrm{COO}\right)_{2} \cdot 4 \mathrm{H}_{2} \mathrm{O}, \mathrm{Na}_{2} \mathrm{SO}_{4}, \mathrm{NaOH}$, and $\mathrm{HClO}_{4}$ were purchased from Fujifilm Wako Pure Chemical (Osaka, Japan). PBI fine powder was obtained from Sato Light Industrial Co., Ltd (Tokyo, Japan) and used as received. A polytetrafluoroethylene filter (pore size $=0.2 \mu \mathrm{m}$, Millipore) was used for filtration. The GCE (outer diameter $=6 \mathrm{~mm}$, inner diameter $=3 \mathrm{~mm}$ ) was purchased from BAS Inc. (Tokyo, Japan). MWCNTs (purity: $\geq 98 \%$, length: $3-6 \mu \mathrm{m}$, outer diameter: $10 \mathrm{~nm} \pm 1 \mathrm{~nm}$, inner diameter: $4.5 \mathrm{~nm} \pm 0.5 \mathrm{~nm}$ ) were purchased from Sigma Aldrich (St. Louis, MO, USA). Co wire (purity: 99.99\%, diameter: $0.50 \mathrm{~mm}$ ) was sourced from Nilaco Co. (Tokyo, Japan). Phosphate solutions (phosphate-buffered saline, PBS) were prepared by mixing solutions of $\mathrm{NaH}_{2} \mathrm{PO}_{4}$ (Fujifilm Wako Pure Chemical) and $\mathrm{Na}_{2} \mathrm{HPO}_{4} \cdot 12 \mathrm{H}_{2} \mathrm{O}$ (Fujifilm Wako Pure Chemical). The solution $\mathrm{pH}$ was adjusted to 4 and 7 with $0.1 \mathrm{M} \mathrm{HClO}_{4}$ and $0.1 \mathrm{M} \mathrm{NaOH}$. All solutions were prepared with deionized water (resistivity $>18.2 \mathrm{M} \Omega \mathrm{cm}$ ) obtained using a Milli-Q water purification system (Millipore, Billerica, MA).

\section{Fabrication of the CoONPs/PBI/MWCNT/GCE electrode}

A schematic of the synthesis of the CoONPs/PBI/MWCNT composite is shown in Fig. 1. PBI (40 mg) was dissolved in DMAc $(10 \mathrm{~mL})$ with 20 min ultrasonication (probe-type BRANSON 5520 sonicator, Kanagawa, Japan), and the solution was

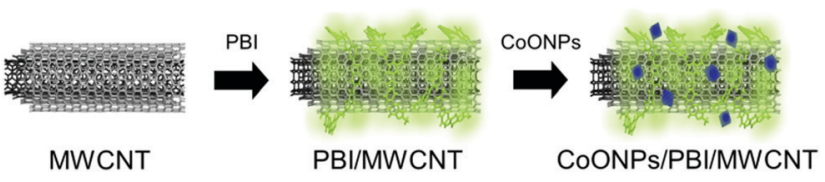

Fig. 1 Schematic of the CoONPs/PBI/MWCNT composite.

supplemented with MWCNTs (10 $\mathrm{mg})$ and sonicated for another $20 \mathrm{~min}$ to prepare the $\mathrm{PBI} / \mathrm{MWCNT}$ dispersion (Fig. S1, ESI $\dagger$ ). This dispersion was treated with $3 \mathrm{~mL}$ of the solution prepared by dissolving $\mathrm{Co}\left(\mathrm{CH}_{3} \mathrm{COO}\right)_{2} \cdot 4 \mathrm{H}_{2} \mathrm{O}(500 \mathrm{mg})$ in deionized water $(10 \mathrm{~mL})$ to obtain a ratio of $3: 1$ $\mathrm{Co}\left(\mathrm{CH}_{3} \mathrm{COO}\right)_{2} \cdot 4 \mathrm{H}_{2} \mathrm{O}$ to $\mathrm{PBI} / \mathrm{MWCNT}$. The reaction mixture was supplemented with PEG400 (reducing agent), heated at $130{ }^{\circ} \mathrm{C}$ for $6 \mathrm{~h}$ in an oil bath upon stirring, filtered, and washed with DMAc to remove excess PBI and PEG400. The GCE was polished with a $0.05 \mu \mathrm{m}$ alumina suspension on a polishing pad, rinsed with Milli-Q water, and sonicated in Milli-Q water for $5 \mathrm{~min}$. Subsequently, a $10 \mu \mathrm{L}(10 \mathrm{mg}$, see ESI $\dagger$ for surface area) aliquot of the CoONPs/PBI/MWCNT dispersion was cast on the polished GCE and dried under vacuum ( $\sim 0.06 \mathrm{MPa}) . \mathrm{A}$ Co wire electrode (prepared by polishing with emery paper (\#2000) and rinsed with Milli-Q water) was used as a reference for comparison with the modified electrode.

\section{Materials characterizations}

Fourier transform infrared (FTIR) spectra were recorded on a VERTEX 70v spectrometer (Bruker Corp., Billerica, MA, USA) using the $\mathrm{KBr}$ method. Thermogravimetric analysis (TGA) was performed using an SII EXSTAR 6000 instrument (Seiko Instruments, Inc., Chiba, Japan) operated in conditioned air from 25 to $700{ }^{\circ} \mathrm{C}$ at a heating rate of $10{ }^{\circ} \mathrm{C} \mathrm{min}^{-1}$. Transmission electron microscopy (TEM) measurements were conducted using an FEI Technai F20 microscope (Tokyo, Japan). X-Ray diffraction (XRD) patterns were recorded using a micro/thin film diffractometer (Rigaku SmartLab) with $\mathrm{Cu} \mathrm{K}_{\alpha}$ radiation $(\lambda=1.54059 \AA)$ at $45 \mathrm{kV}, 200 \mathrm{~mA}$, a scan speed of $0.5^{\circ} \mathrm{min}^{-1}$, and an amorphous Si plate as a sample holder. X-Ray photoelectron spectroscopy (XPS) measurements were conducted using a Shimadzu Kratos AXIS-ULTRA instrument with $\mathrm{Mg} \mathrm{K}_{\alpha}$ radiation $(h \nu=1253.6 \mathrm{eV})$. Peak calibration was performed using the peaks of pure In (99.999\%) at $665.2 \mathrm{eV}$ and $443.7 \mathrm{eV}$ (In $3 \mathrm{~d}_{3 / 2}$ and $3 \mathrm{~d}_{5 / 2}$, respectively).

\section{Electrochemical measurements and ICP measurements}

Electrochemical measurements were conducted using an electrochemical analyzer (model 700B, ALS Co., Ltd, Tokyo, Japan). pH was recorded using a pH meter (AUT-501, DKK-TOA Corp., Tokyo, Japan). Cyclic voltammetry (CV) measurements were performed using a three-electrode system with $\mathrm{Ag}|\mathrm{AgCl}|$ sat. $\mathrm{KCl}$ and a Pt wire as reference and counter electrodes, respectively. Prior to measurements, high-purity $\mathrm{O}_{2}$ (99.99\%) was bubbled through the solutions for at least $30 \mathrm{~min}$. Opencircuit potentials (OCPs) were measured using a two-electrode system with the CoONP-modified electrode as the working 
electrode and $\mathrm{Ag}|\mathrm{AgCl}|$ sat. $\mathrm{KCl}$ as the reference electrode. Inductively coupled plasma (ICP) measurements were performed using a Shimadzu ICPS-8100 instrument (Kyoto, Japan) to confirm the results of OCP measurements for real samples. Prior to real sample measurements, the $\mathrm{pH}$ of the solution was adjusted to $\mathrm{pH} 4$ and 7 .

\section{Results and discussion}

\section{Characterization of CoONPs/PBI/MWCNTs}

TEM imaging of the CoONPs/PBI/MWCNTs composite (Fig. 2) revealed black dots attached to the MWCNTs (as indicated by the red arrows), which indicated that the CoONPs were uniformly deposited on the MWCNTs without forming aggregates. The zoomed-in image of the CoONPs/PBI/MWCNTs reveals that the NPs were closely contacted the MWCNT surface, together with the Co exposure over the PBI layer.

FTIR measurements were conducted to verify the MWCNT functionalization with PBI (Fig. S4 and Table S1, ESI $\dagger$ ). The amount of PBI was determined to be $7.4 \mathrm{wt} \%$ from the weight loss differences (TGA) between MWCNTs and PBI/MWCNTs (Fig. S5, ESI $\dagger$ ). FTIR measurements and TGA demonstrated the successful incorporation of PBI onto the MWCNTs. The thin wrapping of PBI around the MWCNTs enabled the efficient and homogeneous loading of Co on the latter. Without the presence of PBI, well-defined crystalline $\mathrm{CoO}$ nanoparticles with no aggregation failed to form (Fig. S6, ESI $\dagger$ ). Moreover, PBI is known to effectively solubilize CNTs by acting as an exfoliator and individually wrapping CNTs based on $\pi-\pi$ interactions. ${ }^{31}$ PBI also serves as an active binding site, as it is strongly

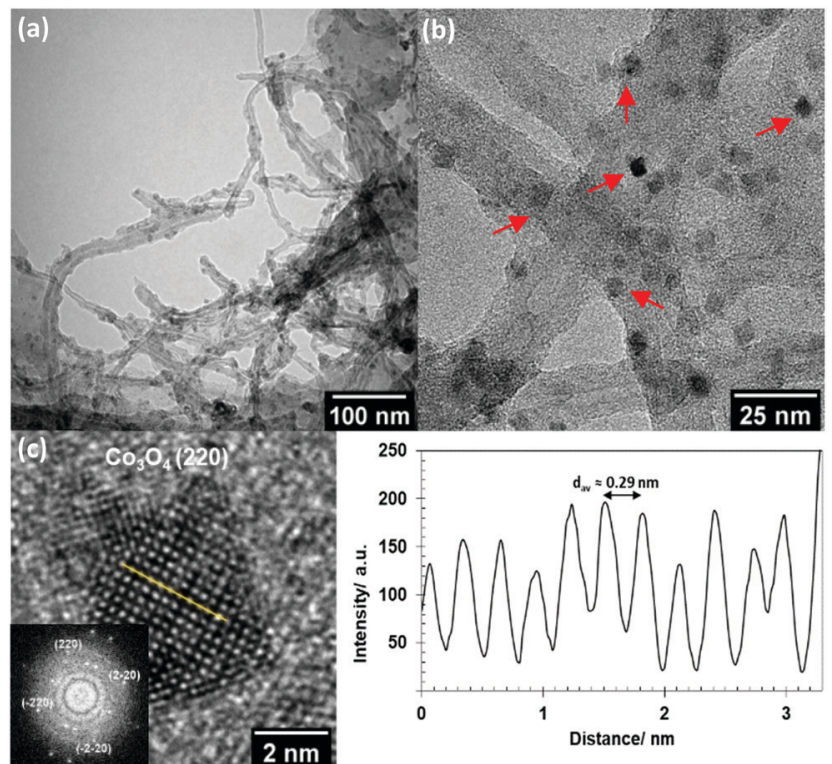

Fig. 2 (a) TEM plane views of CoONPs/PBI/MWCNTs, (b) zoomed-in TEM plane views of COONPs/PBI/MWCNTs with red arrows pointing toward the CoONPs and (c) estimation of the interplanar distance in CoONPs where the intensity pattern shown is across the yellow line in the high-resolution lattice fringe image (HRLFI). The inset figure in (c) shows the corresponding fast Fourier transform (FFT) pattern. adsorbed at the surface of pristine graphitized carbon (e.g., MWCNTs), and can strongly bind metal ions ${ }^{32}$ such as $\mathrm{Au},{ }^{33}$ $\mathrm{Pd}^{34}$ and $\mathrm{Pt}^{35,36}$ by coordinating them via nitrogen. ${ }^{37}$

Through high-resolution TEM imaging (Fig. 2c), the average lattice spacing of CoONPs was estimated to be $\sim 0.29 \mathrm{~nm}$, which corresponds to the (220) plane of hexagonal $\mathrm{Co}_{3} \mathrm{O}_{4}$. This result agreed with the fast Fourier transform imaging and diffraction simulation results (Fig. S7, ESI $\dagger$ ), confirming the validity of our crystal phase assignment. The elemental compositions of the synthesized materials were probed by energydispersive X-ray spectroscopy (Fig. 3). The obtained composite was shown to contain C (from MWCNTs), Co (from CoONPs), and other elements such as $\mathrm{Cu}, \mathrm{Si}$, and $\mathrm{Cl}$ (from the grid support film) (Table S2, ESI $\dagger$ ). The CoONPs appeared to have a uniform size with an average diameter of 3.5-5.5 nm (Fig. 4). The narrow size distribution and well-defined limited crystal surface of the CoONPs provide the advantages of a large specific surface area (with no aggregation) and high sensitivity to phosphate. Given that the properties of metal NPs are often strongly size-dependent, the narrow size distribution of the CoONPs was expected to limit the effect of nanoparticle size variation on phosphate ion detection. The crystal phases and Co valence states were further probed by XRD (Fig. 5) and XPS (Fig. 6).

Diffraction peaks from Fig. 5 at $2 \theta=25.58^{\circ}$ and $42.85^{\circ}$ characteristic of the (002) and (101) planes of the MWCNTs (JCPDS Card No. 75-1621) were observed for all samples, along with those of the CoONPs. Although the diffraction peaks for CoONPs appeared rather small and noisy, at least every peak could be distinguished and all of them agreed well with the crystal structures of $\mathrm{Co}_{3} \mathrm{O}_{4}$ (JCPDS Card No. 74-1657) and cubic CoO (JCPDS Card No. 78-0431). The peak at $36.21^{\circ}$ was ascribed to the (111) plane of $\mathrm{CoO}$, while those at 31.70, 36.55, 44.65, and $59.09^{\circ}$ were attributed to the (220), (311), (400), and (511) planes of $\mathrm{Co}_{3} \mathrm{O}_{4}$, respectively. Thus, the CoONPs largely contained $\mathrm{Co}_{3} \mathrm{O}_{4}$ with a small amount of cubic CoO, i.e., they exhibited a rather simple biphasic composition.

The survey X-ray photoelectron spectrum of CoONPs/PBI/ MWCNTs (Fig. 6a) showed that this nanocomposite mainly contained Co, O, N (due to PBI), and C. The C 1s spectrum (Fig. 6b) was deconvoluted into six peaks at 283.43, 284.45,

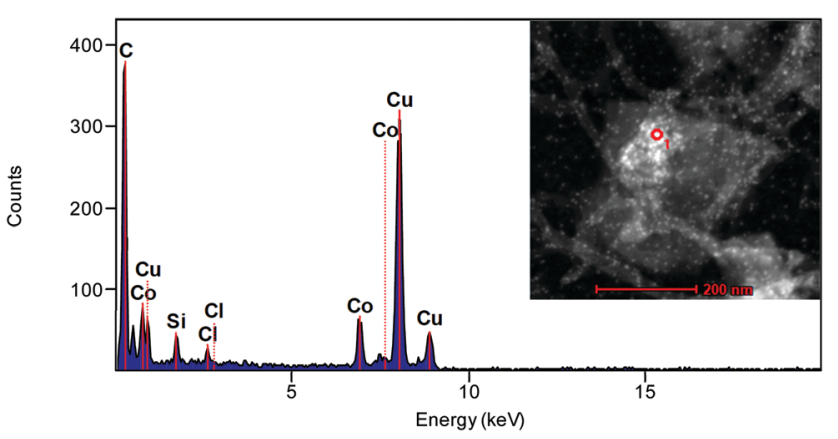

Fig. 3 Energy-dispersive X-ray spectrum of CoONPs/PBI/MWCNTs. Inset image shows the area measured (red circle) from the TEM microphotograph of COONPs/PBI/MWCNTs. 


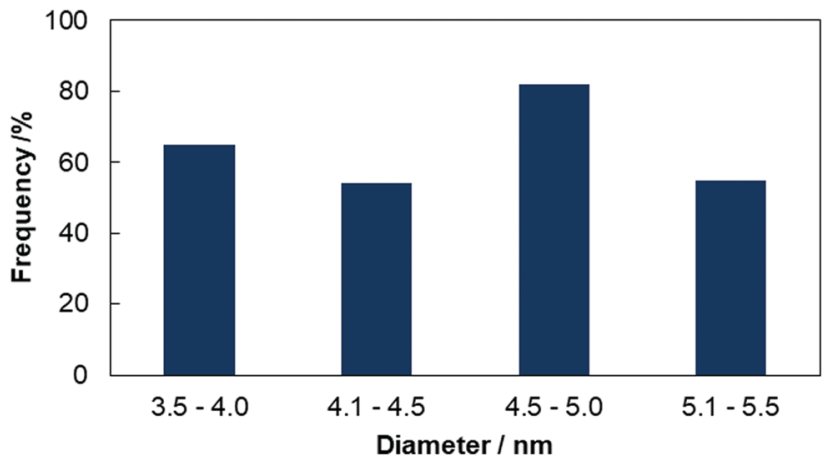

Fig. 4 Size distribution of CoONPs.

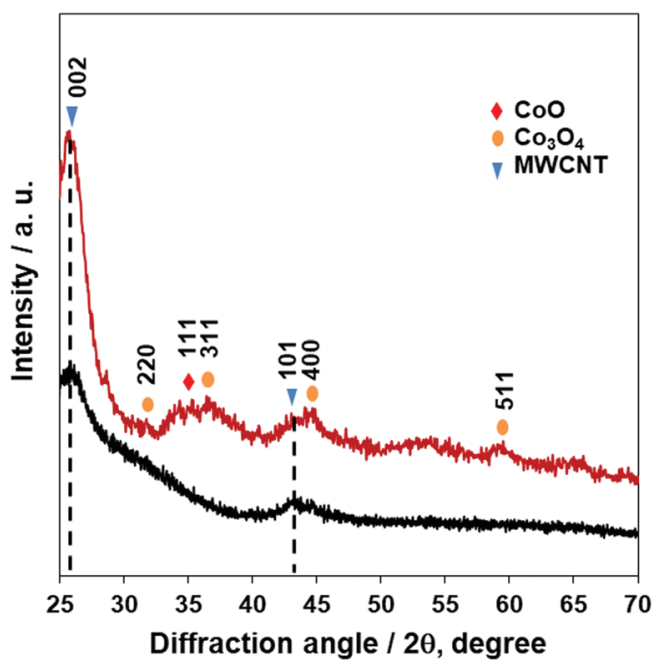

Fig. 5 XRD patterns of (black line) pristine MWCNTs and (red line) COONPS/PBI/MWCNTs.

285.15, 286.26, 288.14, and $291.02 \mathrm{eV}$, which were attributed to $\mathrm{C} \equiv \mathrm{C}$, main peak of $\mathrm{sp}^{2}$ hybridized carbon $\mathrm{C}-\mathrm{C} / \mathrm{C}=\mathrm{C},{ }^{38} \mathrm{C}=\mathrm{N} /$ $\mathrm{C}-\mathrm{O}$ which may arise from the nitrogenous carbon precursors and formation of interfacial $\mathrm{C}-\mathrm{O}-\mathrm{Co}$ bonds from combination between carbon materials with Co oxide, ${ }^{39,40} \mathrm{C}-\mathrm{N} / \mathrm{C}=\mathrm{O}$, $\mathrm{O}-\mathrm{C}=\mathrm{O}$ bonds, and $\pi-\pi$ interactions, respectively.

The $\mathrm{N}$ 1s spectrum (Fig. 6c) was deconvoluted into four peaks at $398.4,399.5,400.1$, and $401.3 \mathrm{eV}$, which were attributed to $-\mathrm{N}=$ pyridinic $\mathrm{N},-\mathrm{NH}-$ pyrrolic $\mathrm{N}$, metal-nitrogen bonds of Co-N, and oxidized $\mathrm{N}$ for the $\mathrm{PBI}$, respectively. Fig. 6d displays the related Co 2p spectrum, revealing two main spin orbit lines at $780.1 \mathrm{eV}\left(\mathrm{Co} 2 \mathrm{p}_{3 / 2}\right)$ and $795.68 \mathrm{eV}$ (Co $\left.2 \mathrm{p}_{1 / 2}\right)$, in line with the $\mathrm{Co}^{3+}$ and $\mathrm{Co}^{2+}$ states expected for $\mathrm{Co}_{3} \mathrm{O}_{4}$ and CoO. Each of these main peaks was deconvoluted into three characteristic peaks. Peaks at 780.6 and $795.9 \mathrm{eV}$ were assigned for $\mathrm{Co}-\mathrm{N}$, originated from the interactions of Co with $\mathrm{N}$ of the PBI believed to generate high active sites for oxidation reaction. ${ }^{41}$ The above results agreed well with those of XRD and TEM. Satellite peaks near the Co $2 \mathrm{p}_{3 / 2}$ and Co $2 \mathrm{p}_{1 / 2}$ signals were observed at 773.5, 785.16, and $802.39 \mathrm{eV}$, corresponding to spin orbit components. Satellites are commonly observed for
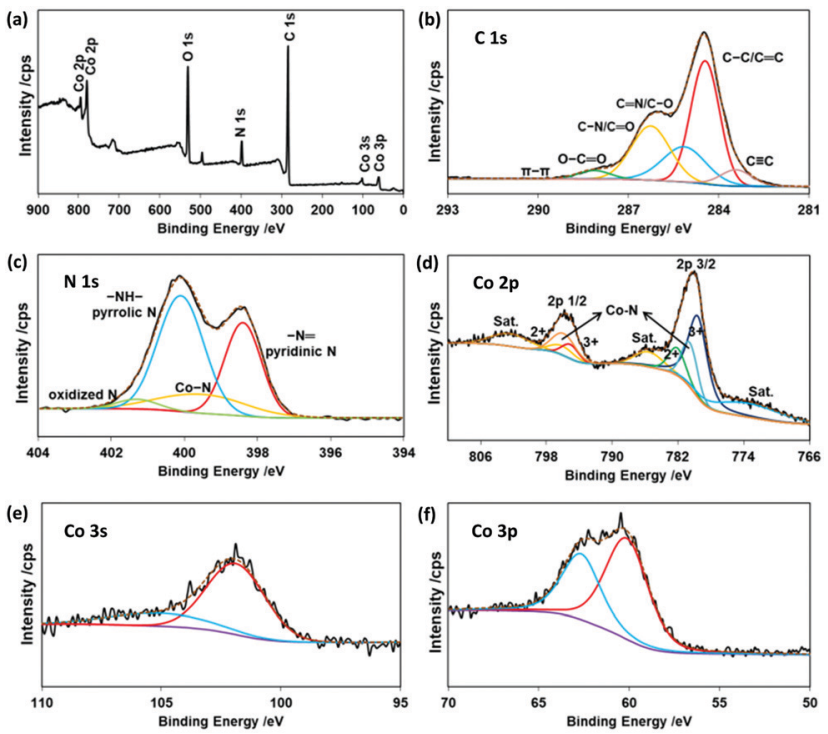

Fig. 6 (a) Survey, (b) C 1s, (c) N 1s, (d) Co 2p, (e) Co 3s, and (f) Co 3p X-ray photoelectron spectra of CoONPs/PBI/MWCNTs.

transition metals. ${ }^{42}$ Therefore, in the case of $\mathrm{Co}_{3} \mathrm{O}_{4}$, which contains both $\mathrm{Co}$ (II) and $\mathrm{Co}$ (III), we expected to see some satellite features due to these states. ${ }^{43}$ The Co $3 \mathrm{~s}$ spectrum of the prepared composite (Fig. 6e) featured a peak at $102.08 \mathrm{eV}$ corresponding to a low-spin $\mathrm{Co}^{3+}$ state. Finally, the Co 3p spectrum (Fig. 6f) featured a peak at $61.33 \mathrm{eV}$. The ratio of $3: 1$ was calculated as amount differences between $\mathrm{Co}_{3} \mathrm{O}_{4}$ and $\mathrm{CoO}$ obtained from each $\mathrm{Co}^{3+}$ and $\mathrm{Co}^{2+}$ peak area from Co $2 \mathrm{p}$ spectra. The presence of $\mathrm{Co}_{3} \mathrm{O}_{4}$ and $\mathrm{CoO}$ was expected to result in high sensitivity to phosphate. Transition metal (e.g., Co) oxides are widely used for sensing because of their surface redox properties. ${ }^{44,45}$ Specifically, the $\mathrm{Co}^{2+}$ and $\mathrm{Co}^{3+}$ states of Co found in our composite are readily accessible and thermodynamically stable. $^{46}$

\section{Electrochemical characterization}

CV curves in phosphate solution were recorded for both the bulk Co wire electrode and CoONPs/PBI/MWCNTs/GCE (Fig. 7). The actual current $v$ s. potential of the CV curves shown on Fig. S8 (ESI $\dagger$ ). The curve of the Co wire electrode recorded in $0.1 \mathrm{M}$ PBS at $\mathrm{pH} 7$ featured one anodic peak around $-0.35 \mathrm{~V}$ and two cathodic peaks around $-0.8 \mathrm{~V}$ and $-1.1 \mathrm{~V}$ (Fig. 7a). Given that this behavior was similar to that previously reported by $\mathrm{Xu}$ et al. ${ }^{20}$ the first cathodic peak was identified as that observed in the absence of $\mathrm{H}_{2} \mathrm{PO}_{4}{ }^{-}$for $\mathrm{Co}$, while the second cathodic peak was attributed to the reduction of $\mathrm{Co}\left(\mathrm{H}_{2} \mathrm{PO}_{4}\right)_{2}$ to $\mathrm{Co}$. The following reactions are believed to occur on the surface of the Co electrode in the tested potential region.

$$
\begin{gathered}
\mathrm{Co}^{2+}+2 \mathrm{e}^{-} \rightleftharpoons \mathrm{Co}, \\
\mathrm{Co}(\mathrm{OH})_{2}+2 \mathrm{e}^{-} \rightleftharpoons \mathrm{Co}+2 \mathrm{OH}^{-}, \\
\mathrm{Co}\left(\mathrm{H}_{2} \mathrm{PO}_{4}\right)_{2}+2 \mathrm{e}^{-} \rightleftharpoons \mathrm{Co}+2 \mathrm{H}_{2} \mathrm{PO}_{4}{ }^{-} .
\end{gathered}
$$

The curve of CoONPs/PBI/MWCNTs/GCE featured one anodic peak around $-0.35 \mathrm{~V}$ (the same as that observed for the Co 
(a)

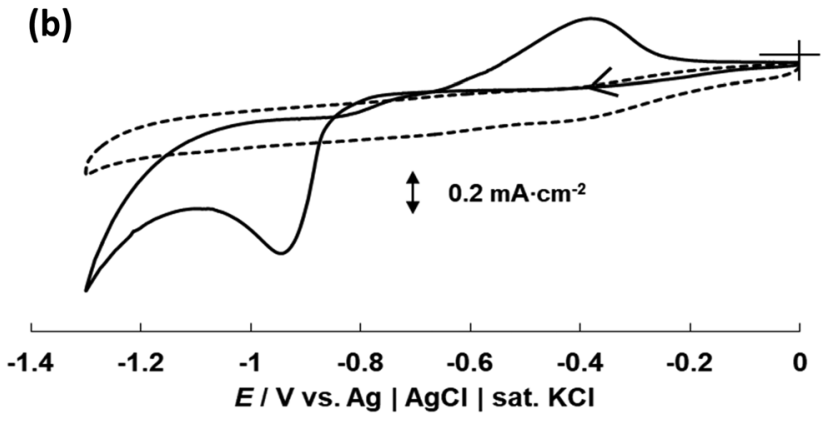

Fig. $7 \mathrm{CV}$ curves recorded at $5 \mathrm{mV} \mathrm{s}^{-1}$ for (a) the bulk Co wire electrode (broken line) and CoONPs/PBI/MWCNTs/GCE (solid line) in 0.1 M PBS with $\mathrm{pH} 7$ and (b) CoONPs/PBI/MWCNTs/GCE in $0.1 \mathrm{M} \mathrm{Na}_{2} \mathrm{SO}_{4}$ (broken line) and $0.1 \mathrm{M}$ PBS with $\mathrm{pH} 7$ (solid line).

wire electrode) and only one cathodic peak at around $-0.9 \mathrm{~V}$. Notably, this cathodic peak was not observed when the measurement was performed in $0.1 \mathrm{M} \mathrm{Na}_{2} \mathrm{SO}_{4}$ (i.e., in the absence of phosphate) (Fig. 7b), and therefore reflected the presence of phosphate ions. Specifically, the cathodic peak was ascribed to the occurrence of reactions (2) and (3), in which case the potential shifted to values more positive than that of the bulk Co wire electrode. This different behavior was also presumably attributed to differences in the exposed crystal planes in bulk Co wire and CoONPs/PBI/MWCNTs, i.e., the CoONPs in CoONPs/PBI/MWCNTs were thought to react with phosphate ions in a different way than polycrystalline bulk Co. TEM, XRD, and XPS results also suggested that the CoONPs contained $\mathrm{Co}_{3} \mathrm{O}_{4}$ and $\mathrm{CoO}$ phases, which ensured a considerably higher sensitivity and selectivity for phosphate ions than that attained for polycrystalline bulk Co. We assumed $\mathrm{Co}_{3} \mathrm{O}_{4}$ might play the main role in sensing phosphate ion as the main crystal phase. In particular, the detection of phosphate by the CoONPs-based electrode was not hindered by the presence of other anions such as $\mathrm{SO}_{4}{ }^{2-}, \mathrm{Cl}^{-}, \mathrm{CH}_{3} \mathrm{COO}^{-}$, and $\mathrm{NO}_{3}{ }^{-}$, unlike that by the Co wire electrode (Fig. S9 and S10, ESI $\dagger$ ). Fig. S11 and S12 (ESI $\dagger$ ) depict the performances of both electrodes at various $\mathrm{pH}$ values.

\section{Potentiometric response}

The dynamic responses of the composite electrode to changes in phosphate concentration at $\mathrm{pH} 4$ and 7 were measured using OCP in a two-electrode system (Fig. 8). These $\mathrm{pH}$ values were selected because the electrode worked best under acidic conditions (i.e., $\mathrm{pH} 4-7$ ). The practical response time was recorded
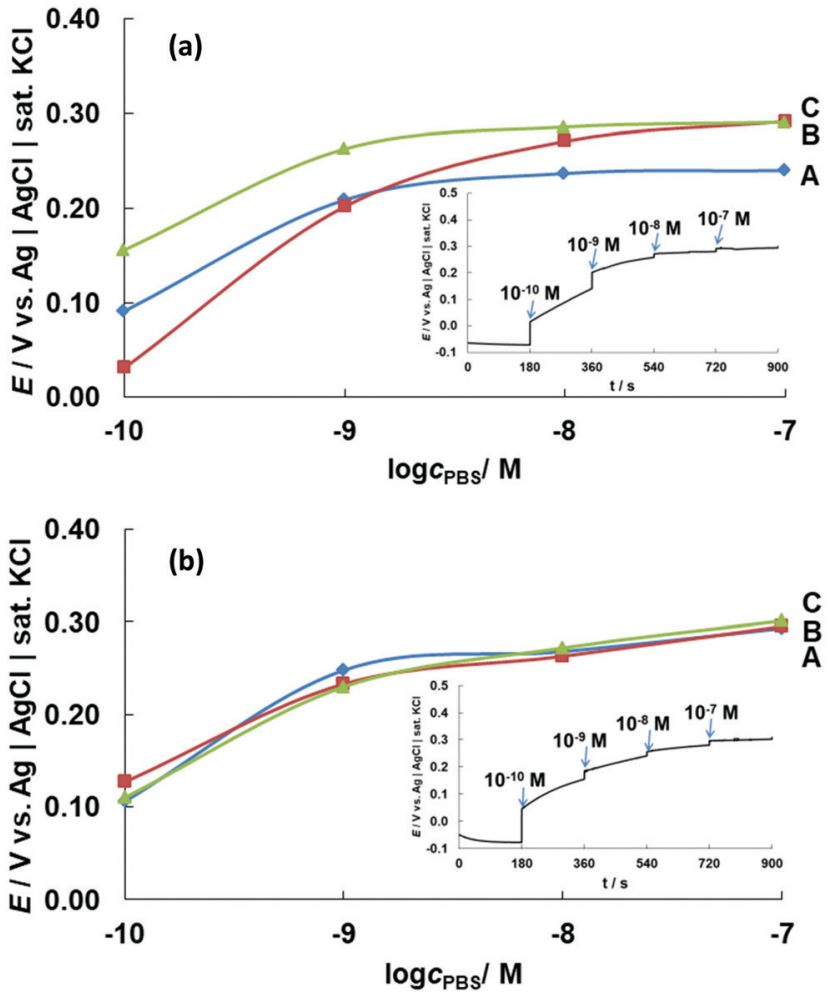

Fig. 8 OCPs $(E)$ obtained for COONPs/PBI/MWCNTs/GCE at different phosphate concentrations $\left(C_{\mathrm{PBS}}=1.0 \times 10^{-10}\right.$ to $\left.1.0 \times 10^{-7} \mathrm{M}\right)$ at $\mathrm{pH}$ (a) 4 and (b) 7. The results of triplicate measurements are marked as A, B, and $C$ and indicate high repeatability.

by varying the concentration of the phosphate solution from $1.0 \times 10^{-10}$ to $1.0 \times 10^{-7} \mathrm{M}$ (equivalent to $0.1-100 \mathrm{nM}$ ) every $3 \mathrm{~min}$. A solution (pH 7) obtained by mixing $0.1 \mathrm{M} \mathrm{NaOH}$ and $0.1 \mathrm{M} \mathrm{HClO}_{4}$ was used as the initial solution. Measurements were conducted in triplicate to confirm the response repeatability.

Fig. 8a shows that the potential commenced at $0.05-0.15 \mathrm{~V}$ for a $0.1 \mathrm{nM}$ phosphate solution at $\mathrm{pH} 4$, increasing to $0.20-0.25 \mathrm{~V}$ as the phosphate concentration increased to $1 \mathrm{nM}$. This significant potential change was observed until the phosphate level reached $\sim 10 \mathrm{nM}$. At higher concentrations, the response curve was almost flat, although the potential still shifted to a more positive value with increasing phosphate concentration. Notably, phosphate detection was impossible in the absence of Co, i.e., for MWCNTs/GCE (Fig. $\mathrm{S} 13, \mathrm{ESI} \dagger$ ) and the absence of PBI for CoONPs/MWCNT/GCE showed disproportionate relationship of potential value with the concentration change unlike the one with PBI (Fig. S14, ESI $\dagger$ ).

The CoONPs-modified electrode could detect phosphate ions at very low concentrations, with the detection range at pH 7 determined as 0.1-100 nM (Fig. 8b). The wide detection range at both $\mathrm{pH} 4$ and 7 enabled the sensing of phosphate at concentrations lower than the eutrophication threshold of $\sim 0.1 \mu \mathrm{M},{ }^{5}$ and our electrode was therefore suitable for phosphate monitoring in environmental samples. While previous studies using similar electrochemical methods reported a response time of 15-60 s, our composite electrode featured a fast response time of $\sim 5 \mathrm{~s}$. The potential response for $10 \mathrm{nM}$ phosphate solution 
Table 1 Comparison of the analytical performances obtained with different detection types for phosphate ions

\begin{tabular}{|c|c|c|c|c|c|}
\hline Detection range & Type of detection & Electrode/reagent & Response time & Real sample & Ref. \\
\hline $50 \mathrm{nM}-5 \mu \mathrm{M}$ & Fluorescence $(590 \mathrm{~nm})$ & Enzymatic system + amplex red & $15 \mathrm{~min}$ & - & 48 \\
\hline Up to $0.434 \mathrm{nM}$ & Colorimetric and ECL & $\mathrm{CoOOH}$ Nanosheet & $10 \mathrm{~min}$ & Tap and river water & 17 \\
\hline $1 \mu \mathrm{M}-10 \mathrm{mM}$ & Spectrophotometric & $\mathrm{Co}_{3} \mathrm{O}_{4}$ Film electrode (transmitted at $620 \mathrm{~nm}$ ) & $50 \mathrm{~s}$ & - & 49 \\
\hline $10 \mu \mathrm{M}-0.1 \mathrm{M}$ & Electrochemical & Co-Based phosphate microelectrode & $<60 \mathrm{~s}$ & Microbial flocs & 50 \\
\hline $10 \mu \mathrm{M}-0.1 \mathrm{M}$ & Electrochemical & Cobalt phosphate coated Co & $30 \mathrm{~s}$ & - & 20 \\
\hline $10 \mu \mathrm{M}-0.1 \mathrm{M}$ & Electrochemical & Co Electrode & $<40 \mathrm{~s}$ & Waste water & 52 \\
\hline $0.1 \mathrm{nM}-0.1 \mu \mathrm{M}$ & Electrochemical & CoONPs/PBI/MWCNT/GCE & $\sim 5 \mathrm{~s}$ & Creek water & This paper \\
\hline
\end{tabular}

pH 7 remained almost unchanged d for 1 month using same electrode stored inside an initial mixed solution of $0.1 \mathrm{M} \mathrm{NaOH}$ and $0.1 \mathrm{M} \mathrm{HClO}_{4}$ when not in use under the condition of room temperature (Fig. S15, ESI $\dagger$ ). The proposed sensor was compared with other types of detection for phosphate ions with respect to the detection range, type of electrode/reagent, and response time (Table 1).

To confirm the fast response of the modified electrode, we performed CV measurements in the presence and absence of phosphate (Fig. 9). The actual current vs. potential of the CV curves shown on Fig. S16 (ESI $\dagger$ ). Redox peaks at 0.15 and $0.27 \mathrm{~V}$ were initially observed for the CoONPs-modified electrode in a mixed solution ( $\mathrm{pH} 4)$ of $0.1 \mathrm{M} \mathrm{NaOH}$ and $0.1 \mathrm{M} \mathrm{HClO}_{4}$ but disappeared after the addition of $0.1 \mathrm{nM}$ phosphate ions (Fig. 9a). The same behavior was also observed for $\mathrm{pH} 7$ (Fig. 9b), in which case the initial peaks were observed at 0.1 and $0.19 \mathrm{~V}$. The addition of phosphate seemed to strongly influence the double-layer capacitance. Thus, phosphate binding occurred on the CoONPs surface even at low phosphate concentrations, which suggested that our composite electrode is capable of highly sensitive phosphate detection.

As mentioned before, cobalt oxides react with phosphate ions in solution to form cobalt phosphate precipitates at the electrode surface, with the precipitate nature depending on $\mathrm{pH}$. Soluble phosphorus in natural water is largely present as four orthophosphates $\left(\mathrm{H}_{3} \mathrm{PO}_{4}, \mathrm{H}_{2} \mathrm{PO}_{4}{ }^{-}, \mathrm{HPO}_{4}{ }^{2-}\right.$, and $\left.\mathrm{PO}_{4}{ }^{3-}\right)$, with the proportions of these species depending on $\mathrm{pH}$ (Fig. S17, ESI $\dagger) .{ }^{53}$ Hem investigated the distribution of orthophosphate species at $25{ }^{\circ} \mathrm{C}$, revealing that no more than two types are present at any $\mathrm{pH}^{54}$ The phosphate species formed herein at pH 4 is thought to be $\mathrm{H}_{2} \mathrm{PO}_{4}{ }^{-}$(eqn (4)), while $\mathrm{H}_{2} \mathrm{PO}_{4}{ }^{-}$and/or $\mathrm{HPO}_{4}{ }^{2-}$ might form at $\mathrm{pH} 7$ (eqn (4) and (5)).

$$
\begin{array}{r}
3 \mathrm{CoO}+2 \mathrm{H}_{2} \mathrm{PO}_{4}{ }^{-}+2 \mathrm{H}^{+} \rightleftharpoons \mathrm{Co}_{3}\left(\mathrm{PO}_{4}\right)_{2}+3 \mathrm{H}_{2} \mathrm{O}, \\
3 \mathrm{CoO}+2 \mathrm{HPO}_{4}{ }^{2-}+\mathrm{H}_{2} \mathrm{O} \rightleftharpoons \mathrm{Co}_{3}\left(\mathrm{PO}_{4}\right)_{2}+4 \mathrm{OH}^{-} .
\end{array}
$$

\section{Phosphate ion monitoring in real water samples}

The CoONPs/PBI/MWCNT electrode was used to monitor phosphate ions in creek water samples collected around Saga City, Japan. Before measurements, the sample $\mathrm{pH}$ was adjusted to pH 4 or 7 to ensure that the electrode worked under optimal
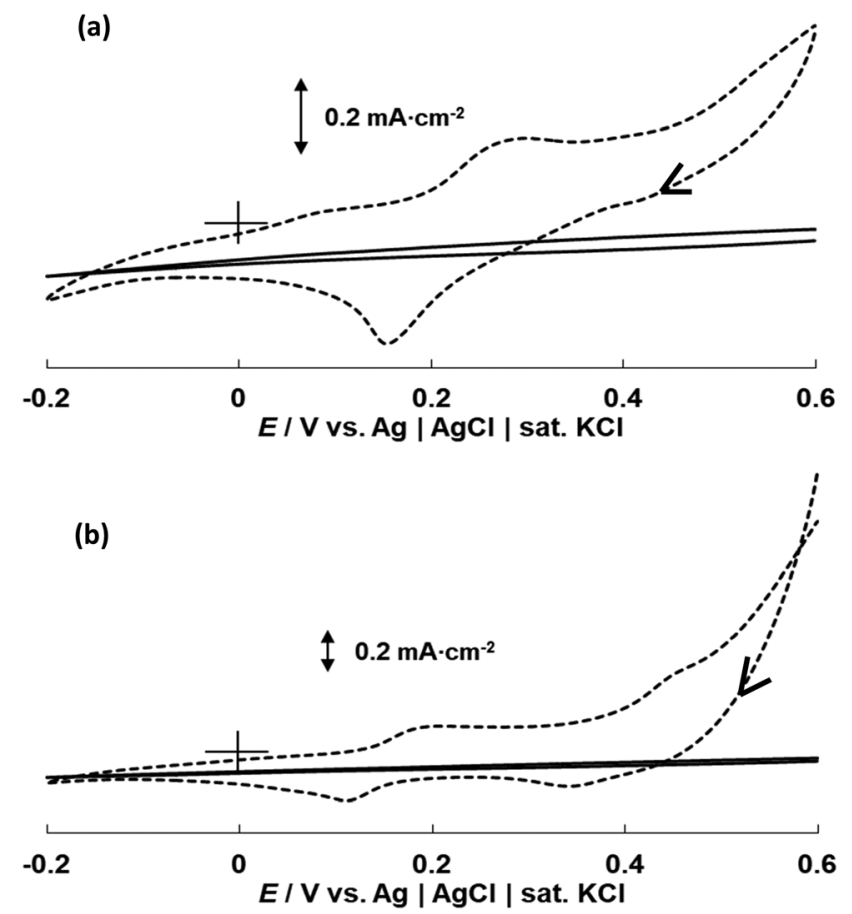

Fig. $9 \mathrm{CV}$ curves of CoONPs/PBI/MWCNTs/GCE recorded in a mixed solution of $0.1 \mathrm{M} \mathrm{NaOH}$ and $0.1 \mathrm{M} \mathrm{HClO}_{4}$ (broken line) and in $0.1 \mathrm{nM}$ PBS (solid line) at (a) $\mathrm{pH} 4$ and (b) $\mathrm{pH} 7$ using a scan rate of $5 \mathrm{mV} \mathrm{s}^{-1}$.

conditions, and phosphate levels were determined by matching the potential values to the OCPs obtained at these $\mathrm{pH}$ values. The final concentration of phosphate was determined by adding phosphate to the analyzed samples to obtain a total concentration of $10 \mu \mathrm{M}$, and the validity of the obtained concentration was confirmed by ICP measurements. The phosphate additions were performed because the exceptionally low concentration of phosphate in the analyzed samples complicated its analysis by ICP with limited range detection for comparison and validation.

An OCP of $0.28 \mathrm{~V}$ was obtained at $\mathrm{pH} 4$, indicating that the phosphate concentration was between $1.0 \times 10^{-2}$ and $10 \mu \mathrm{M}$. Furthermore, the OCP obtained at $\mathrm{pH} 7(0.31 \mathrm{~V})$ indicated that the phosphate concentration was between 1 and $10 \mu \mathrm{M}$. The 
Table 2 Concentrations of phosphate ions in real water samples

\begin{tabular}{|c|c|c|c|c|c|c|}
\hline $\begin{array}{l}\text { Sample } \\
\text { no. }\end{array}$ & $\mathrm{pH}$ & $\begin{array}{l}\text { Intended conc./ } \\
\mu \mathrm{M}\end{array}$ & $\begin{array}{l}\text { ICP result/ } \\
\text { ppm }\end{array}$ & $\begin{array}{l}\text { ICP conc./ } \\
\mu \mathrm{M}\end{array}$ & $\begin{array}{l}E_{\mathrm{OCP}} / \\
\mathrm{V}\end{array}$ & $\begin{array}{l}\text { OCP conc./ } \\
\mu \mathrm{M}\end{array}$ \\
\hline 1 & 4 & $5-55$ & 0.45 & 9.4 & 0.28 & $\sim 10$ \\
\hline 2 & 7 & $5-55$ & 0.36 & 7.5 & 0.31 & $\sim 10$ \\
\hline
\end{tabular}

combined results suggested that the level of phosphate in the analyzed sample was approximately $10 \mu \mathrm{M}$. This result was in good agreement with that of the ICP measurements, indicating the suitability of our electrode for purely electrochemical phosphate quantitation (Table 2).

\section{Conclusions}

A new phosphate ion sensor based on CoONPs hybridized with PBI and MWCNTs was developed. The synthesized CoONPs were shown to be well dispersed on the MWCNTs and exhibit a uniform size of 3.5-5.5 $\mathrm{nm}$, mainly comprising hexagonal $\mathrm{Co}_{3} \mathrm{O}_{4}$ with a fraction of CoO. The effects of morphology and microstructure on electrochemical performance were investigated to reveal that the CoONPs-containing electrode exhibited a considerably higher sensitivity than that of the bulk Co wire electrode. Specifically, the former electrode could sense phosphate at pH 4 and 7 and at concentrations (0.1-100 nM) lower than the eutrophication threshold. The CoONPs/PBI/MWCNT electrode was successfully used to detect phosphate in actual creek water samples.

\section{Author contributions}

Shaimah Rinda Sari: data curation, formal analysis, investigation, methodology, writing - original draft; Masayuki Tsushida: resources, formal analysis, investigation, validation; Tetsuya Sato: resources, formal analysis, investigation, validation; Masato Tominaga: conceptualization, investigation, funding acquisition, writing - review \& editing, supervision.

\section{Conflicts of interest}

There are no conflicts to declare.

\section{Acknowledgements}

We are grateful to Professor Keisuke Ohto (Saga University) for help with ICP measurements. This work was supported by the Nanotechnology Platform Program (Molecule and Material Synthesis) of the Ministry of Education, Culture, Sports, Science and Technology (MEXT), Japan (Grant no. JPMXP09 S20KU0040, JPMXP09 S21KU0041). We also acknowledge support in the form of research equipment sharing by the MEXT Project for Promoting the Public Utilization of Advanced Research Infrastructure (Program for Supporting the Introduction of the New Sharing System; Grant no. JPMXS0422400020).

\section{Notes and references}

1 R. G. Wetzel, Limnology: Lake and River Ecosystems, Academic Press, San Diego, 3rd edn, 2001, pp. 239-288.

2 J. L. Domagalski and H. Johnson, Phosphorus and Groundwater: Establishing Links Between Agricultural Use and Transport to Streams, U.S. Geological Survey Fact Sheet 2012-3004, 2012, p. 4.

3 S. O. Engblom, Biosens. Bioelectron., 1998, 13, 981-994.

4 N. C. Hanson, T. C. Daniel, A. N. Sharpley and J. L. Lemunyon, J. Soil Water Conserv., 2002, 57, 408-417.

5 C. Forano, H. Farhat and C. Mousty, Curr. Opin. Electrochem., 2018, 11, 55-61.

6 R. Tirado and M. Allsopp, Greenpeace Research Laboratories Technical Report (Review) 02-2012, https:/www. greenpeace.to/greenpeace/wp-content/uploads/2012/06/tiradoand-allsopp-2012-phosphorus-in-agriculture-technical-report-022012.pdf (accessed May 2021).

7 J. L. Haberer and J. A. Brandes, Mar. Chem., 2003, 82, 185-196.

8 J. Murphy and J. P. Riley, Anal. Chim. Acta, 1962, 27, 31-36.

9 S. Lee, K. K. Y. Yuen, K. A. Jolliffe and J. Yoon, Chem. Soc. Rev., 2015, 44, 1749-1762.

10 V. E. Zwicker, G. E. Sergeant, E. J. New and K. A. Jolliffe, Org. Biomol. Chem., 2021, 19, 1017-1021.

11 J. Cleary, C. Slater, C. McGraw and D. Diamond, IEEE Sens. J., 2008, 8, 508-515.

12 E. Climent, R. Casasús, M. D. Marcos, R. Martínez-Máñez, F. Sancenón and J. Soto, Dalton Trans., 2009, 4806-4814.

13 L. A. Shaver, J. Chem. Educ., 2008, 85, 1097-1098.

14 L. Szekers, E. Kardos and G. L. Szekeres, Microchem. J., 1966, 11, 1-12.

15 P. J. Antony, S. Karthikeyan and C. S. P. Iyer, J. Chromatogr. B: Anal. Technol. Biomed. Life Sci., 2002, 767, 363-368.

16 M. T. Galceran, M. Diez and L. Paniagua, J. Chromatogr. A, 1993, 657, 77-85.

17 H. Cheng, P. Hui, J. Peng, W. Li, W. Ma, H. Wang, J. Huang, X. He and K. Wang, Anal. Chem., 2021, 93(17), 6770-6778.

18 G. P. Ratkovski, K. T. O. do Nascimento, G. C. Pedro, D. R. Ratkovski, F. D. S. Gorza, R. J. da Silva, B. G. Maciel, L. C. Mojica-Sánchez and C. P. de Melo, Langmuir, 2020, 36(11), 2920-2929.

19 A. T. Lawal and S. B. Adeloju, Talanta, 2013, 114, 191-203.

20 K. Xu, Y. Kitazumi, K. Kano and O. Shirai, Electrochim. Acta, 2018, 282, 242-246.

21 D. Xiao, H.-Y. Yuan, J. Li and R.-Q. Yu, Anal. Chem., 1995, 67, 288-291.

22 S. G. Hosseini, S. J. H. Toloti and K. Babaei, et al., J. Therm. Anal. Calorim., 2016, 124, 1243-1254.

23 K. Kargosha, P. Hemmatkhah and S. H. Ahmadi, Anal. Bioanal. Electrochem., 2017, 9, 521-534.

24 E. T. Thostenson, C. Li and T. W. Chou, Compos. Sci. Technol., 2005, 65, 491-516.

25 L. Li and Y. Xing, J. Power Sources, 2008, 178, 75-79.

26 W. Li, C. Liang, J. Qiu, W. Zhou, H. Han, Z. Wei, G. Sun and Q. Xin, Carbon, 2002, 40, 787-790. 
27 Y. Lin, F. Lu, Y. Tu and Z. Ren, Nano Lett., 2004, 4, 191-195.

28 Y. Pan, Y. Chen, Y. Lin, P. Cui, K. Sun, Y. Liu and C. Liu, J. Mater. Chem. A, 2016, 4, 14675-14686.

29 J. Tian, Q. Liu, A. M. Asiri and X. Sun, J. Am. Chem. Soc., 2014, 136, 7587-7590.

30 C. Gao, Z. Guo, J.-H. Liu and X.-J. Huang, Nanoscale, 2012, 4, 1948-1963.

31 T. Fujigaya and N. Nakashima, Adv. Mater., 2013, 25, 1666-1681.

32 A. A. D’Archivio, L. Galantini, A. Biffis, K. Jeřábek and B. Corain, Chem. - Eur. J., 2000, 6, 794-799.

33 M.-Y. Hua, H.-C. Chen, R.-Y. Tsai and C.-S. Lai, Talanta, 2011, 85, 631-637.

34 L. F. Villalobos, R. Hilke, F. H. Akhtar and K.-V. Peinemann, Adv. Energy Mater., 2018, 8, 1701567.

35 M. R. Berber, H. Elkhenany, I. H. Hafez, A. El-Badawy, M. Essawy and N. El-Badri, Nanomedicine, 2020, 15, 793-808.

36 E. O. Eren, N. Özkan and Y. Devrim, Int. J. Hydrogen Energy, 2021, 46, 29556-29567.

37 M. Okamoto, T. Fujigaya and N. Nakashima, Adv. Funct. Mater., 2008, 18, 1776-1782.

38 R. Li, Z. Wei, X. Gou and W. Xu, RSC Adv., 2013, 3, 9978-9984.

39 M. M. Zhang, R. Li, X. X. Chang, C. Xue and X. L. Gou, J. Power Sources, 2015, 290, 25-34.

40 Y. Meng, G. Wang, M. Xiao, C. Duan, C. Wang, F. Zhu and Y. Zhang, J. Mater. Sci., 2017, 52, 13192-13202.
41 Y. Chen, S. Jie, C. Yang and Z. Liu, Appl. Surf. Sci., 2017, 419, 98-106.

42 S. Chenakin and N. Kruse, Appl. Surf. Sci., 2020, 515, 146041.

43 S. Farid, W. Qiu, J. Zhao, X. Song, Q. Mao, S. Ren and C. Hao, J. Electroanal. Chem., 2020, 858, 113768.

44 A. Zecchina, D. Scarano, S. Bordiga, G. Spoto and C. Lamberti, Adv. Catal., 2001, 46, 265-397.

45 N. Barsan, D. Koziej and U. Weimar, Sens. Actuators, B, 2007, 121, 18-35.

46 S. C. Petitto, E. M. Marsh, G. A. Carson and M. A. Langell, J. Mol. Catal. A: Chem., 2008, 281, 49-58.

47 L. Drummond and W. Maher, Anal. Chim. Acta, 1995, 302, 69-74.

48 M. J. Vazquez, B. Rodriguez, C. Zapatero and D. G. Tew, Anal. Biochem., 2003, 320, 292-298.

49 Y. Shimizu and Y. Furuta, Solid State Ionics, 1998, 241, 113-115.

50 W. H. Lee, Y. W. Seo and P. L. Bishop, Sens. Actuators, B, 2009, 137, 121-128.

51 Z. Zou, J. Han, A. Jang, P. L. Bishop and C. H. Ahn, Biosens. Bioelectron., 2007, 22, 1902-1907.

52 L. Zhu, X. Zhou and H. Shi, Front. Environ. Sci. Eng., 2014, 8, 945-951.

53 S. Engblom, Plant Soil, 1999, 206, 173-179.

$54 \mathrm{~J}$. Hem, Study and Interpretation of the Chemical Characteristics of Natural Water, U.S. Geological Survey Water Supply Paper, 1992, p. 2254. 